\title{
Design and Implementation of Navi-guide Device
}

\author{
Sampada H K, M S Lathashree, Likitha V, Arya L Gowda, H R Pramath
}

\begin{abstract}
The device designed is a navigation guide which will help the user with turn by turn directions. At the present time, use of smartphones for the navigation support has been increased and this in turn leads to risk of accident. The navi-guide device displays step by step direction on the OLED screen. This reduces the chances of mishaps and the increases the user focus. The navi-guide app has been developed for better user interface. The rider will have to just connect his phone to the device via bluetooth can safely reach his destination without any distractions with the aid of this device.
\end{abstract}

Key Terms: Navi-guide App, Smart Navigation, Location, Route.

\section{INTRODUCTION}

The device built mainly aims at the common public who are daily commuters. The food delivering agencies is another domain which can use this device very efficiently. Auto, taxi and truck drivers can also make use of this device to reach their respective destination. Often we will have to travel across many areas or locations where we will not know the exact route. We obviously use our mobile phone to know the directions.

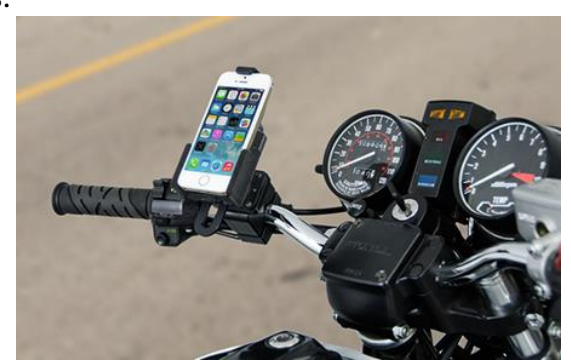

Figure 1: Mounting of mobile on handlebar

Manuscript received on July13, 2021.

Revised Manuscript received on August 02, 2021.

Manuscript published on July 30, 2021.

* Correspondence Author

Sampada $\mathbf{H} \mathbf{K}$, Professor, Department of Electronics and Communication, Atria Institute of Technology, Bangalore, India. Email: mslathashree@gmail.com

M S Lathashree*, Student, Department of Electronics and Communication, Atria Institute of Technology, Bangalore, India. Email: mslathashree@gmail.com

Likitha V, Student, Department of Electronics and Communication, Atria Institute of Technology, Bangalore, India. Email: likitha0109@gmail.com

Arya L Gowda, Student, Department of Electronics and Communication, Atria Institute of Technology, Bangalore, India. Email: aryalgowda918@gmail.com

Pramath H R, Student, Department of Electronics and Communication, Atria Institute of Technology, Bangalore, India. Email: hrpramath@gmail.com

(C) The Authors. Published by Blue Eyes Intelligence Engineering and Sciences Publication (BEIESP). This is an open access article under the CC BY-NC-ND license (http://creativecommons.org/licenses/by-nc-nd/4.0/)
Now a days, for the food delivering agents, using their smartphones for navigation has become the major part of their work. The delivery agents mount the phones on their vehicles and travel. This practice will damage the phone, interrupts the concentration of the rider and also the chances of accidents will increase and this can ruin the valuable life of the rider.

It is not a good practice to use the earphones while travelling to listen the voice instructions. In many situations, even though the agents could get through the directions, they will not be able to find the exact or accurate location. In turn they rely on their customers for obtaining the exact location. This could get frantic for the customer and leads to his /her dissatisfaction.

The main aim of our device is to provide accurate and turn by turn directions to the user and they can overcome all the above mentioned problems with the use of the same.The navi-guide device will help the user in the following way. The user needs to connect his/her phone to the device by the means of Bluetooth. In the phone, set the starting point and the destination location of the ride in the installed navi-guide app. Keep the phone safe aside and follow the OLED screen for the directions. The device is provided with a proper casing and is placed on the vehicle of the rider which he can use in any environment.

The following is the order of the paper structure. Firstly, the hardware and the software parts have been given with a brief description. Introduction to the entire process of the device is given which is followed by a flowchart for both the device and the app and the block diagram proposed for the same. We depict the working and the results obtained of the system using the snapshots. Lastly, we conclude with the advantages and limitations of the device and also the development which can be done in the future.

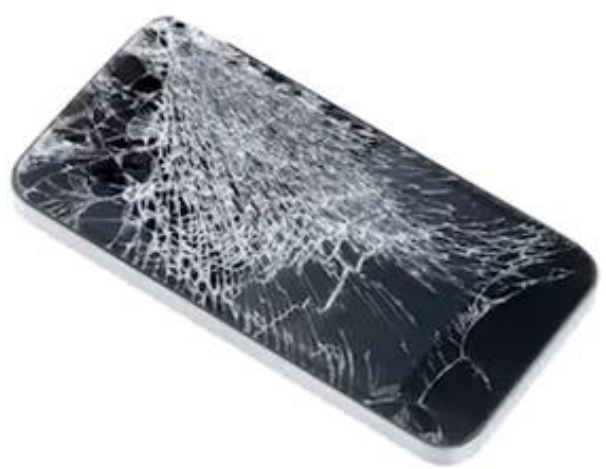

Figure 2: Damaged Smartphone

Published By:

Blue Eyes Intelligence Engineering and Sciences Publication (BEIESP) (C) Copyright: All rights reserved.

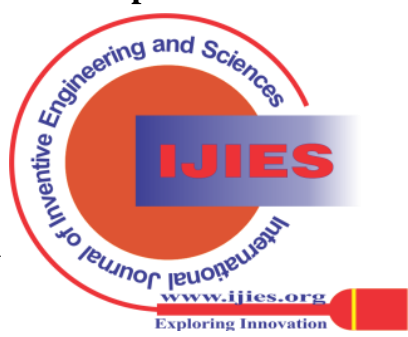




\section{COMPONENT DESCRIPTION}

\section{A. ESP32 Microcontroller:}

ESP 32 microcontroller gathers the information from all the modules and performs action to display the results on the OLED screen .The microcontroller has $520 \mathrm{~kb}$ SRAM,448 kib ROM , wi-fi and Bluetooth module. It has 34 programmable GPIOs, 4 SPIs, 2I2Cs, 3UART , Ethernet and MAC interface.It has security features like WFA, WPA/WPA2, secure boot and flash encryption. Engineered for mobile devices, wearable electronics and IoT applications, ESP32 achieves ultra-low power consumption with a combination of several types of proprietary softwares. ESP32 can perform as a complete standalone system or as a slave device to a host MCU, reducing communication stack overhead on the main application processor. It also accesses the external QSPI flash and SRAM through high-speed caches. Up to 16Mbytes of the external flash are

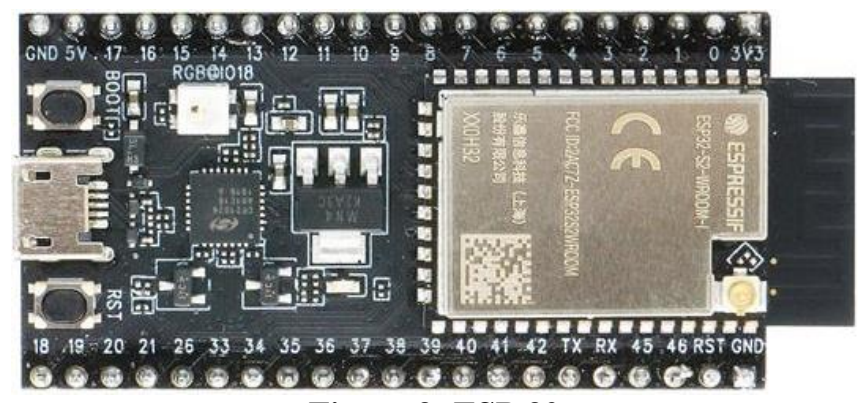

Figure 3: ESP 32

\section{B. Magnetometer:}

Magneto meter is used to provide the information about the magnetic field and this can expose the location of the user. Magnetometer extends the Generic Sensor API to provide information about the magnetic field as detected by the device's primary magnetometer sensor. The magnetometer sensor measures the magnetic field for all three physical axes (x, y, z) in $\mu \mathrm{T}$ (micro Tesla).

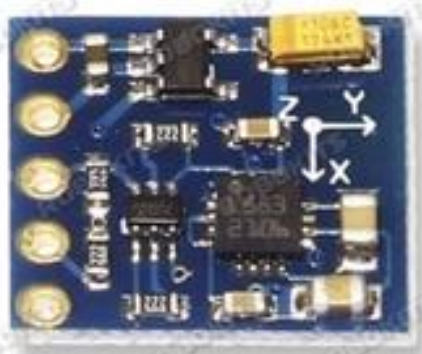

Figure 4: MagnetometerQMC5883

\section{OLED Screen:}

organic light emitting diode also known as organic electroluminescent diode is a light emitting diode in which the emissive electroluminescent layer is the film of organic compound that emits light in responsive to electric current. OLEDs are used to create digital displays in devices such as television screens, computer monitors, portable systems such as smart phones and handheld game consoles. memory-mapped onto the CPU code space.

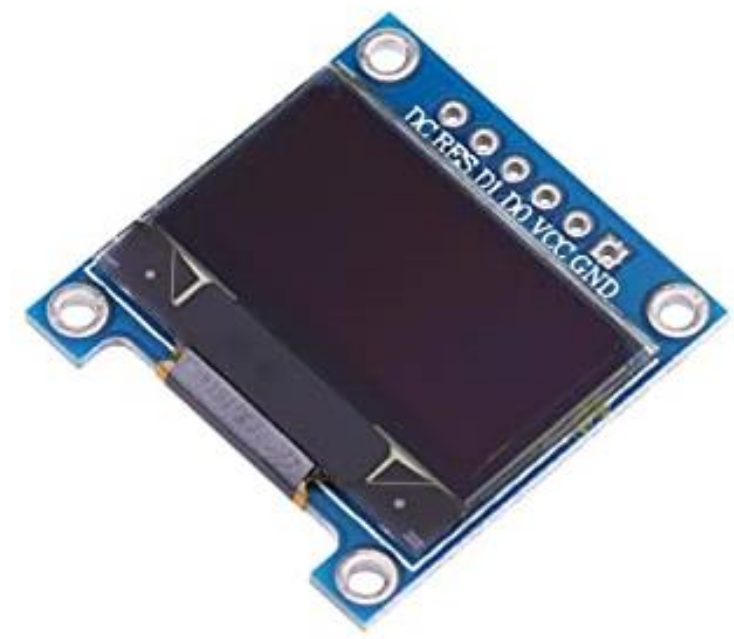

Figure 5: OLED screen

\section{Arduino IDE:}

It is an integrated development environment and an open source arduino software in which writing, uploading and executing the code can be done with any arduino board. We can browse the full range official arduino products like boards, modules, shields and kits.we can easily integrate all these and work with them.

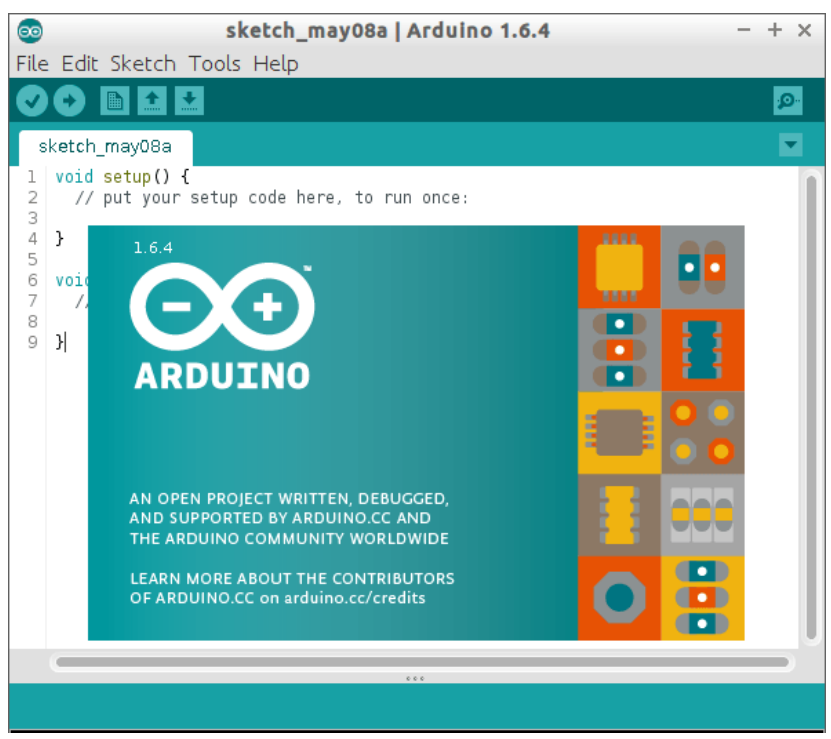

Figure 6: Arduino IDE

\section{E. MIT App inventor:}

It is a web application integrated development environment. It allows the users to computer programming to create new application software. It uses a graphical user interface (GUI) very similar to the programming languages and the StarLogo, which allows users to drag and drop visual objects to create an application that can run on android devices. It also supports the use of cloud data. 


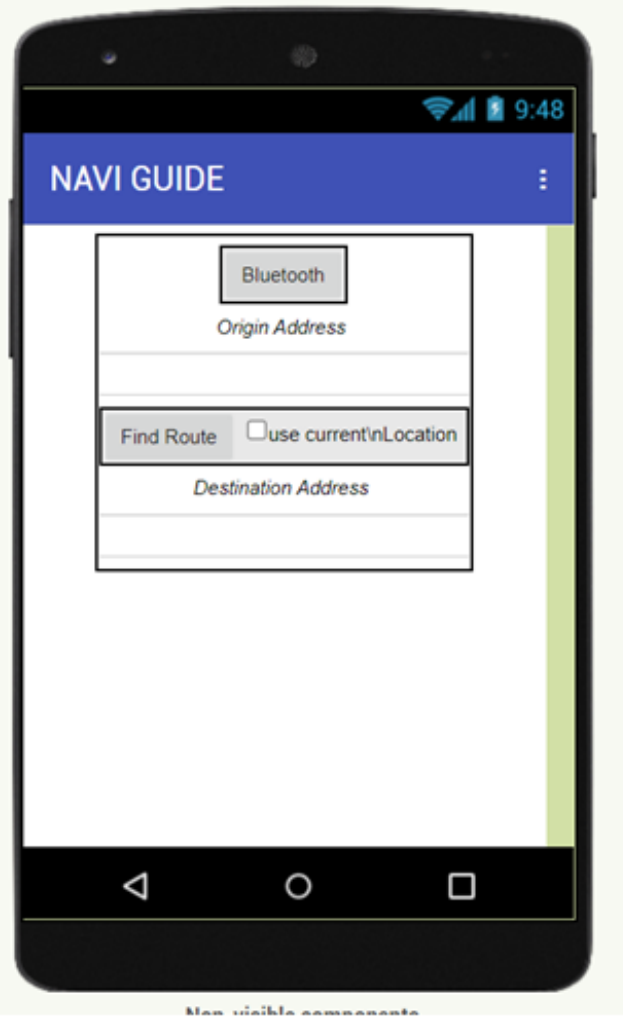

III. DESCRIPTION OF THE SYSTEM

The main goal of our system is to provide turn-by-turn directions to the user. In order to achieve this, we first have to connect the device and verify its Bluetooth connection with the smartphone. Then launch the navi-guide app which is installed in user's mobile phone. Once we launch the app, necessary details are given i.e., start address and also the destination address. These details are routed to ESP32. The microcontroller performs necessary action and shows the directions on the OLED screen. Once the user reaches the destination, device goes off. The other ways when our device goes OFF is when we does not provide any necessary details or when ESP doesnot receive any instruction.

WORKING OF THE APP: To get started with the app, firstly launch the app in the mobile phone. Now the mobile has to be connected to our device through the means of Bluetooth and verify whether our device is connected or not. Once it is connected we can type the start address or we can even set the start address and lastly type the destination address where you want to reach. After providing both start address and destination address, our device shows us the directions on the OLED screen.

This feature is beneficial for daily commuters, delivery agents as it eliminates the possibility of mishaps.

The following flowchart gives a brief description of the flow of the Navi Guide Device

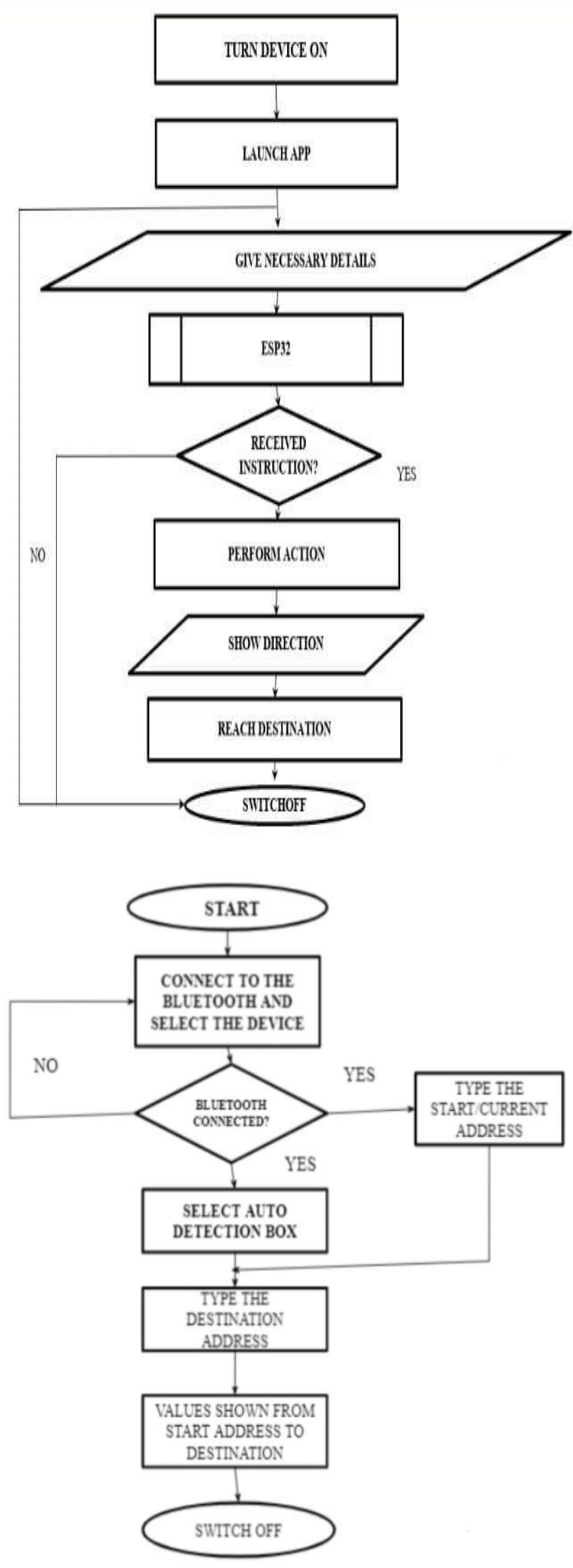

Published By:

Blue Eyes Intelligence Engineering and Sciences Publication (BEIESP)

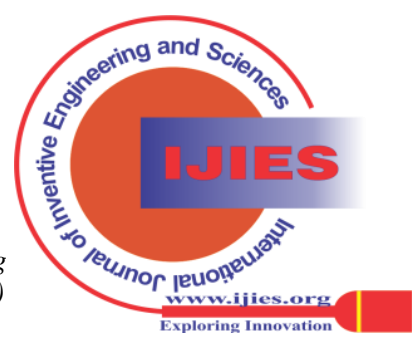




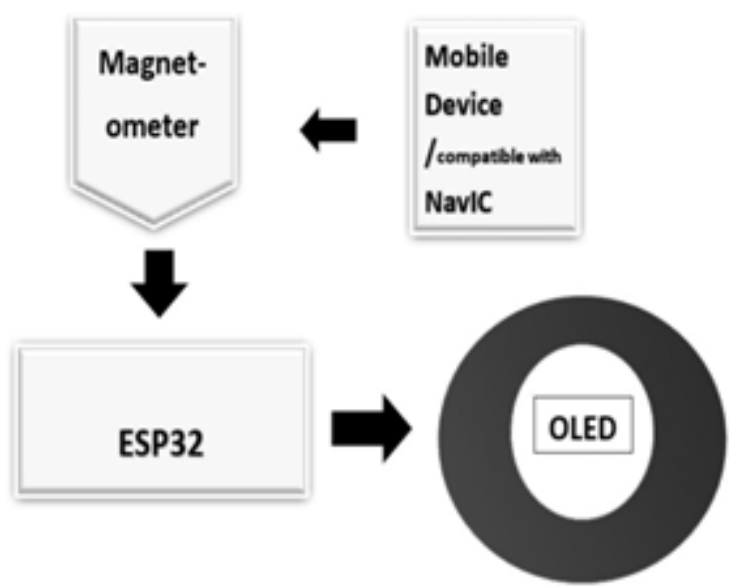

IV. ALGORITHM OF THE SYSTEM

Algorithm for the General Flow

1. START

2. Turn ON the device

3. Launch the Navi Guide App installed in user's mobile phone

4. Provide start address and the destination address details

a)If received by the device, then perform the action

5. STOP

b)Else the device goes OFF.

\section{Algorithm for the App}

1. START

2. Connect the user's mobile phone to the selected device through Bluetooth

3. Verify the Bluetooth connection,

a)If connected select location detection box

b)Else again try connecting to the device.

4. Type the destination address

5. Values will be shown from start address to the destination address which are provided by the user in the previous step

6. STOP

\section{RESULTS OBTAINED}

IV. The following are the snapshots of the device.

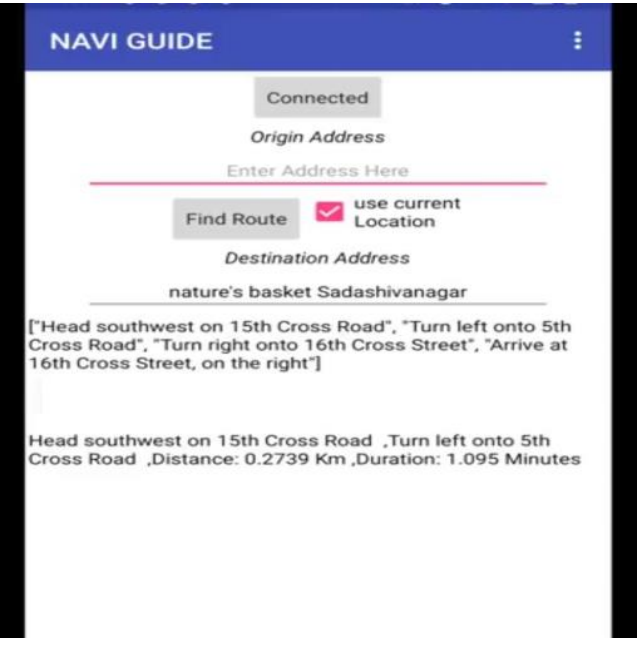

Retrieval Number: 100.1/ijies.I92900710921
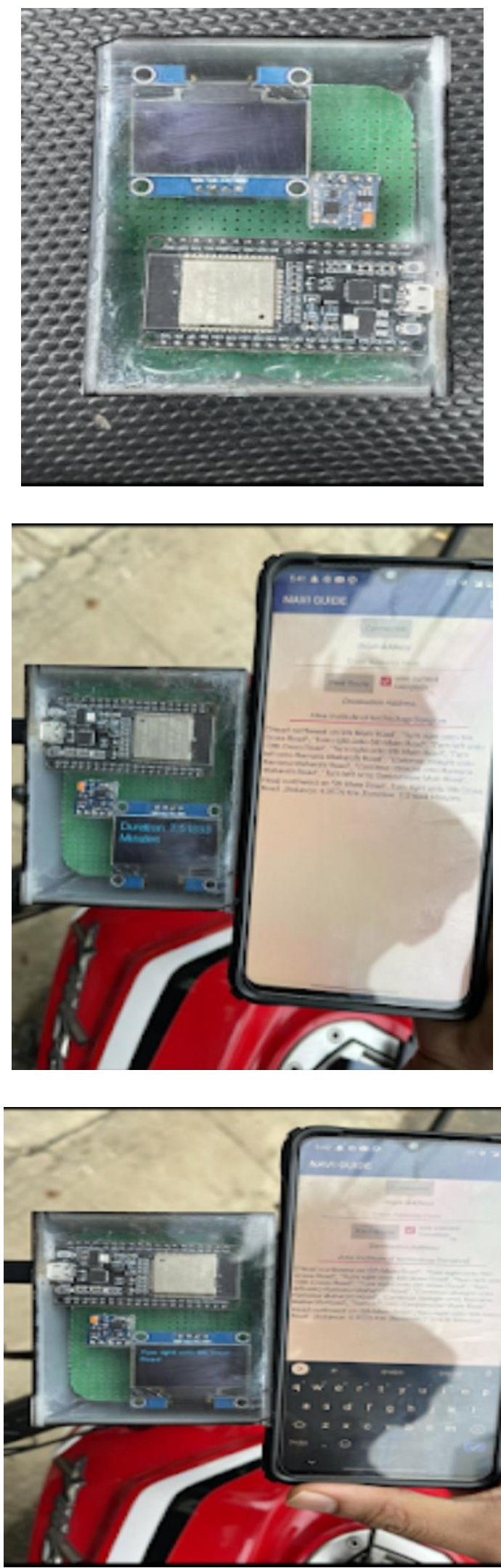

Published By:

Blue Eyes Intelligence Engineering and Sciences Publication (BEIESP) (C) Copyright: All rights reserved.

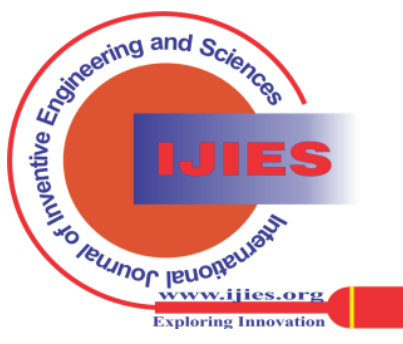



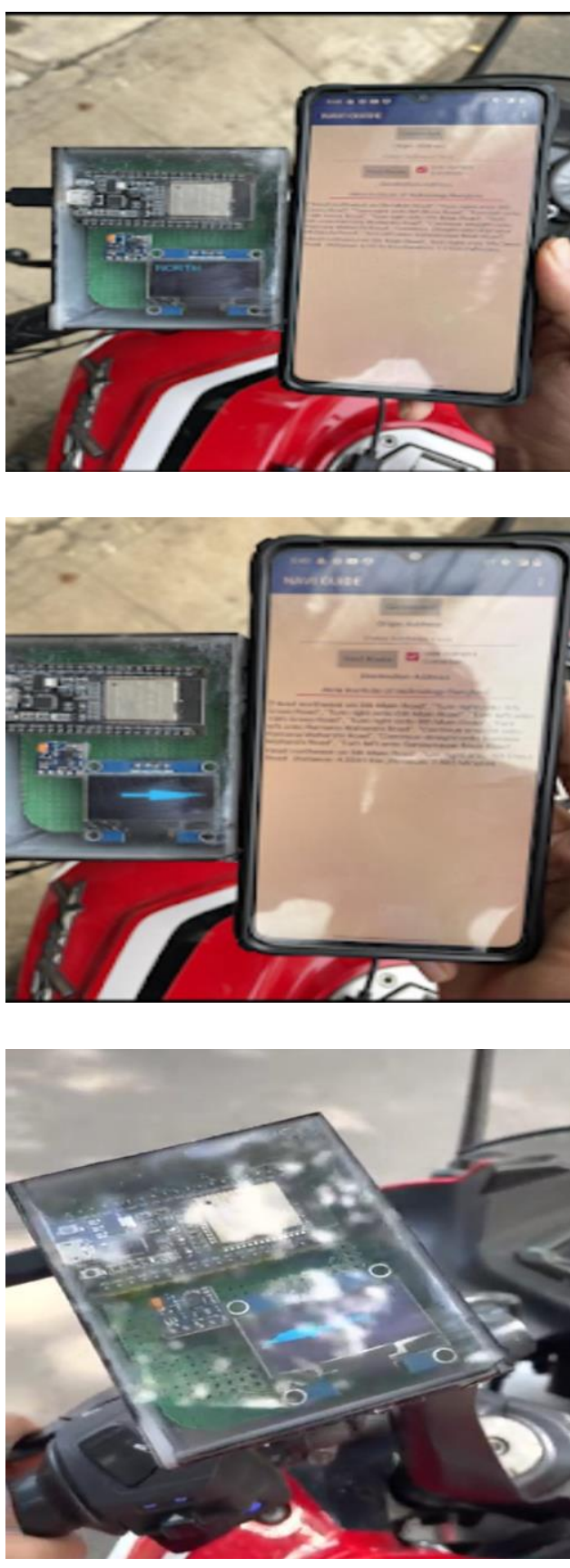

\section{ADVANTAGES AND DISADVANTAGES}

The advantages of using this system are as follows:

- Eliminates the possibility of mishaps and allows the user to increase his focus while navigating.

- Totally prevents the accidental damage to the mobile as it eliminates the need to mount the phone on the vehicle.

The disadvantages of using this system are as follows:

- Accuracy in operation is dependent on the connectivity of the mobile phone.

- Cannot function independently.

\section{FUTURE SCOPE}

The following improvements can be made in order to improve the system:

- Refreshing rate of the device can be improved.

- Better app user interface.
- Implementation of the system within the core of smart vehicles instead of using a discrete device.

\section{CONCLUSION}

In conclusion, this system can redefine the conventional navigating system by giving turn-by-turn directions which will be highly beneficial in the delivery industries. As the automobile industries are heading towards the implementation of smart and the autonomous vehicles, this system could be included as a part of the vehicle itself. Further, the future scope of this device is huge, as mentioned above.

\section{REFERENCES}

1. Wang B.J., Yang C.H., Gu Z.Y. (2018) Smart Flashlight: Navigation Support for Cyclists. In: Marcus A., Wang W. (eds) Design, User Experience, and Usability: Users, Contexts and Case Studies. DUXU 2018. LectureNotes in Computer Science, vol 10920. Springer, Cham. https://doi.org/10.1007/978-3-319-91806-8_31

2. Trent M., Abdelgawad A., Yelamarthi K. (2017) A Smart Wearable Navigation System for Visually Impaired. In: Gaggi O., Manzoni P., Palazzi C., Bujari A., Marquez-Barja J. (eds) Smart Objects and Technologies for Social Good. GOODTECHS 2016. Lecture Notes of the Institute for Computer Sciences, Social Informatics and Telecommunications Engineering, vol 195. Springer, Cham. https://doi.org/10.1007/978-3-319-61949-1_35

3. A. Devi, M. J. Therese and R. S. Ganesh, "Smart Navigation Guidance System for Visually Challenged People," 2020 International Conference on Smart Electronics and Communication (ICOSEC),Trichy,India, 2020, pp. 615-619, doi: 10.1109/ICOSEC49089.2020 9215289..

4. Agrawal, Tarun\& Qadeer, Mohamaad. (2018). Tracing Path with Arduino Uno using GPS andGPRS/GSM. 1203- 1208. 10.1109/GUCON.2018.8674953.

5. P. Dutta and U. S. G. V. Dontiboyina, "NaviRide: Smart Bicycle Computer with GPS Waypoint Indicators," 2016 Second International Conference on Computational Intelligence \& Communication Technology (CICT), Ghaziabad, 2016, pp. 472-477, doi: 10.1109/CICT.2016.100.

6. Kawamura T., Umezu K., Ohsuga A. (2008) Mobile Navigation System for the Elderly - Preliminary Experiment and Evaluation. In Sandnes F.E., Zhang Y., Rong C., Yang L.T., Ma J. (eds) Ubiquitous Intelligence and Computing. UIC 2008. Lecture Notes in Computer Science, vol 5061. Springer, Berlin, Heidelberg. https://doi.org/10.1007/978-3-540-69293-5 45

7. Larin, V.B., Tunik, A. On inertial navigation system error correction. Int Appl Mech 48, 213-223 (2012) https://doi.org/10.1007/s10778-012-0517-y

8. K. Rajan , E. Kalaiselvan, 2015, Intelligent Navigation System for Blind People with Real Time Tracking, INTERNATIONAL JOURNAL OF ENGINEERING RESEARCH \& TECHNOLOGY (IJERT) NCEASE - 2015 (Volume 3 - Issue 22).

9. Kumar, P.M., Gandhi, U., Varatharajan,R. et al.Intelligent face recognition and navigation system using neural learning for smart security in Internet of Things. Cluster Comput 22, 7733-7744 (2019). https://doi.org/10.1007/s10586-017-1323-4

10. Biral, F., Bosetti, P.\&Lot, R. Experimental evaluation of a system for assisting motorcyclists to safely ride road bends. Eur. Transp. Res. Rev. 6, 411-423 (2014). https://doi.org/10.1007/s12544-014-0140-6

11. L. Velmurugan, G. Raghuraj and J. Simon, "Google Glass Based GPS Navigation Using Smartwatch," 2017 IEEE International Conference on ComputationalIntelligence and Computing Research (ICCIC), Coimbatore, 2017, pp. 1-5, doi: 10.1109/ICCIC.2017.8524238.

12. P. Kanani and M. Padole,"Real-time LocationTracker for Critical Health Patient using Arduino, GPS Neo6m and GSM Sim800L in Health Care," 2020 4th International Conference on Intelligent Computing and Control Systems (ICICCS), Madurai,India, 2020, pp. 242-249, doi: 10.1109/ICICCS48265.2020.9121128.

Published By:

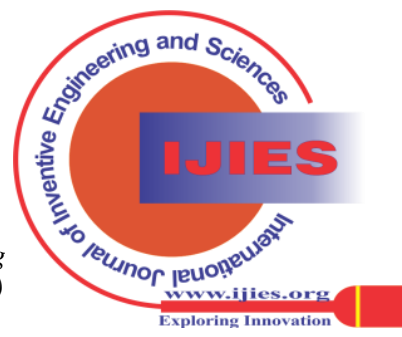


13. S. Lee, G. Tewolde and J. Kwon, "Design and implementation of vehicle tracking system using GPS/GSM/GPRS technology and smartphone application," 2014 IEEE World Forum on Internet of Things (WF-IoT), Seoul, 2014, pp. 353-358, doi: 10.1109/WF-IoT.2014.6803187.S. Zhang, C. Zhu, J. K. O. Sin, and P. K. T. Mok,"A novel ultrathin elevated channel low-temperature poly-Si TFT," IEEE Electron Device Lett., vol. 20, pp. 569-571, Nov. 1999.

14. B. S. Goh et al.,"IoT Based Indoor Locating System (ILS) using Bluetooth Low Energy (BLE)," 2020 IEEE International Conference on Consumer Electronics(ICCE), Las Vegas, NV, USA, 2020, pp. 1-4, doi: 10.1109/ICCE46568.2020.9043108.

15. W. Wongthai, S. Khruahong, P. Srithong and M. Samphao-ngoen, "The Development of an Internet of Things Mobile Application for Tracking an Electric Bus in a Campus," 2019 Joint International Conference on Digital Arts, Media and Technology with ECTI Northern Section Conference on Electrical, Electronics, Computer and Telecommunications Engineering (ECTI DAMTNCON), Nan, Thailand, 2019, pp. 220-224, doi: 10.1109/ECTI-NCON.2019.8692244.

16. P. Chang, J. M. Lin and Y. Lo, "Integrated Smart Car Navigation and Voice Control System Design," IECON 2006 - 32nd Annual Conference on IEEE Industrial Electronics, Paris, 2006, pp. 760-765, doi: 10.1109/IECON.2006.347590.

17. Beheshti, E., Van Devender, A.,\&Horn, M.(2012).Touch, click, navigate. Proceedings of the 2012 ACM International Conference on Interactive Tabletops and Surfaces - ITS'12. doi:10.1145/2396636.2396669 FLEXChip Signal Processor (MC68175/D), Motorola, 1996.

18. Wang, Yang \&Beullens, Patrick \& Liu, Honghai\& Brown, David \& Thornton, Tim \& Proud, Richard. (2008). A Practical Intelligent Navigation System based on Travel Speed Prediction. IEEE Conference on Intelligent Transportation Systems, Proceedings, ITSC. 470 - 475. 10.1109/ITSC.2008.4732635.

19. Serrão, M.\&Shahrabadi, Saeed\& Moreno, M.\&José, João \& Rodrigues, José \& Rodrigues, Joao \& du Buf, J..(2014). Computer vision and GIS for the navigation of blind persons in buildings. Univ Access Inf Soc. 14. 1-14. 10.1007/s10209-013-0338-8.J.Padhye, V. Firoiu, andD. Towsley, "A stochastic model of TCP Reno congestion avoidance and control," Univ. of Massachusetts, Amherst, MA, CMPSCI Tech. Rep. 99-02, 1999.

20. Hlaing, Ni \& Naing, Ma \& Naing, San. (2019). GPS and GSM Based Vehicle Tracking System. International Journal of Trend in Scientific Research and Development. Volume-3. 271-275. 10.31142/ijtsrd23718.

\section{AUTHORS PROFILE}

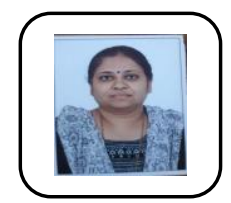

Sampada $\mathbf{H} \mathbf{K}$, Professor in electronics and communication department at Atria institute of technology, Bangalore.

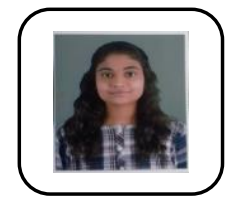

M S Lathashree, student in electronics and communication department, Atria institute of technology, Bangalore.

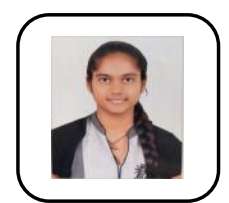

Likitha $\mathbf{V}$, student in electronics and communication department, Atria institute of technology, Bangalore.

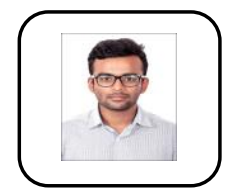

Arya L Gowda, student in electronics and communication department, Atria institute of technology. Bangalore.

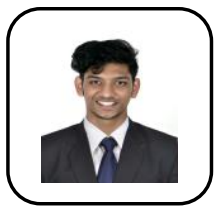

H R Pramath, student in electronics and communication department, Atria institute of technology. Bangalore.

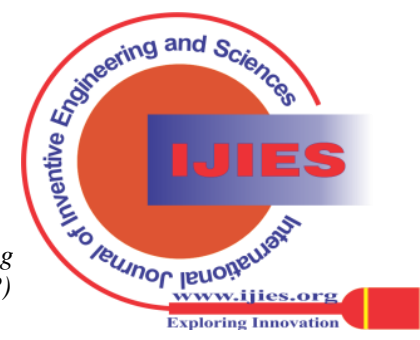

